\section{What happens to the body when one works at night?}

\author{
O que acontece com o corpo quando \\ se trabalha à noite?
}

Claudia Roberta de Castro Moreno 1 Fernando Mazzilli Louzada 2

\section{Chronobiology: the study of biological rhythms}

1 Centro de Pós-graduação, Universidade do Sul de Santa Catarina, Tubarão, Brasil. 2 Departamento de Ciências Biológicas, Universidade Federal do Paraná, Curitiba, Brasil.

Correspondência C. R. C. Moreno Centro de Pós-graduação, Universidade do Sul de Santa Catarina. Rua Marcolino Martins Cabral 39, Tubarão, SC 88701-000, Brasil. cmoreno@unisul.br

\begin{abstract}
The objective of this paper is to present some recent chronobiological findings related to shift and night worker adaptation. First, some key chronobiological concepts concerning the human species are presented. The authors then discuss the possible impacts of work schedules on shift workers' and night workers' health. Finally, countermeasures that might allow adjusting the workers' biological rhythm to shift and night work are discussed.
\end{abstract}

Night Work; Shift Work; Occupational Health; Chronobiology
Our social life is governed by three different clocks: the solar clock, that is, the alternation between day and night, the social clock, which we see or feel at the beginning of a day's journey, and the biological clock 1 . The interaction between these three clocks results in rhythmic behaviors called circadian rhythms, each lasting around 24 hours. The sleep/wake cycle, the alternation between sleep and wakefulness, is the most evident of such rhythms. A detailed observation of the way our bodies work allows a description of several circadian rhythms within the different body systems; it can thus be stated that the essence of living matter lies in rhythmicity. Such rhythms establish temporal relations or phase relations which constitute the so-called internal temporal order. After nightfall, before people fall asleep, their plasma melatonin levels increase. Before dawn an increase in plasma cortisol occurs, preparing the body for wakefulness. During pre-dawn hours the body temperature drops to its minimum, reaching its maximum in the early evening.

The current idea that a biological clock in the hypothalamus controls the expression of such rhythms should be expanded to incorporate other structures both inside and outside the nervous system and participating in the socalled circadian timing system, essentially a 
multioscillatory system. Cultures of nerve cells and other tissues (such as liver and lung) display self-sustained circadian oscillations, demonstrating that numerous tissues have molecular clocks capable of generating and maintaining circadian oscillations.

Recent studies suggest that the hypothalamic suprachiasmatic nuclei (known for some decades as the mammals' biological clock) act not as pacemakers but as internal synchronizers, thus allowing different levels of synchronization within our bodies 2 . Internal synchronization is the timed coordination of multiple individual oscillators, without the need for an external Zeitgeber ${ }^{3}$.

Based on the above concepts, maintenance of the organism's temporal order can be said to depend on two basic processes: the synchronizing effect of environmental cycles - or external Zeitgebers - represented by the solar and social clocks through a process called entrainment, and the interaction between the organism's oscillators, which allows internal synchronization. Entrainment depends on a cascade of events, beginning with the perception of light by the retinal ganglion cells. Processing of such information by the central nervous system allows entrainment, triggering the internal synchronization process. In order to trigger this process, the central nervous system uses different output signals to spread the circadian message throughout the brain and body 4 . This process involves direct and indirect neuronal projections and secretion of polypeptides 5 . The internal synchronization process is based on multiple feedback mechanisms, resulting in a coordinated rhythmicity of the organism's physiology and behavior. One can thus understand the mechanisms through by which changes in the social clock are able to modify the functioning of virtually the entire organism. Changes in the internal temporal order are frequently associated with several diseases 6 .

The relationship between the circadian rhythms and Zeitgebers can be described through phase response curves (PRCs). A PRC is derived by applying a given stimulus at different times or at circadian phases and measuring the effect on the phases of the circadian system. For example, light "pulses" applied before the time the core body temperature drops to its minimum level, that is, in the first half of the night, produces phase delays, whereas light "pulses" applied after the time the core body temperature reaches its minimum level (at the end of the night) produces phase advances. The magnitude of the phase shift depends on the intensity and duration of exposure to light, although this relation is non-linear. Since the human circadian system has an endogenous period slightly longer than $24 \mathrm{~h}$, it tends to drift later and later each day 7 . Phase delays therefore occur more readily than phase advances in the human species.

Detailing the mechanisms involving synchronization processes allows understanding both their plasticity and their limits. One of the most important findings is that the human species is diurnal. Although there are marked individual differences in preferences for sleep and wakefulness schedules, in the human species night and sleep are events that should always occur simultaneously.

Several recent studies have attempted to establish the biological basis for individual differences comprising the circadian timing system, from which the so-called chronotype originates. Such studies suggest that differences in diurnal preferences, which allow classifying morning and evening individuals, may be related to polymorphisms in the genes that make up the human species' molecular clock 8,9.

\section{Swimming against the tide}

The maintenance of stability between the solar, social, and biological clocks goes almost unnoticed throughout the lifetime of a person who works during the day and sleeps at night. On the other hand, night workers suffer from the incompatibility between their work schedule and family/social engagements. As with night workers, shift workers are subject to problems arising from the temporal contradictions to which they are exposed.

Shift work is characterized by the continuity of production or provision of services, which is only possible with several teams of workers at the same workplace. These teams can either change their time of work or work under a fixed schedule, including night shifts. Both changes in schedules and night work can be factors for several diseases, such as gastric, cardiovascular, and sleep disorders.

For example, gastric disorders can be related to changes in dietary habits as a consequence of the work schedule. Many workers increase their coffee, alcohol, and drug consumption, presumably to help stay awake.

In a study of 40 truck drivers working under fixed schedules (only during regular working hours) and truck drivers who had irregular schedules (including night work), Pasqua et al. 10 compared the consumption of food and drugs. Most truck drivers exposed to irregular sched- 
ules $(83.3 \%)$ consumed an average of 54 stimulant pills (pills that stimulate the central nervous system) per month. On the other hand, consumption of stimulants by truck drivers working regular schedules was much lower; a low percentage $(6.3 \%)$ stated that they consumed an average of 0.5 pills per month. In addition to drug consumption to stay awake, most night workers change their dietary habits as a function of the availability of food during the early morning hours. According to Waterhouse et al. 11, night workers have an altered food intake during the working hours when compared to days off and are more dependent on snacks than day workers.

Assis 12 studied the dietary habits of garbage collectors in the city of Florianópolis, Santa Catarina State, Brazil, according to the shift (morning, evening, and night). During the night and in the early morning hours, night workers usually had meals and snacks with a higher caloric content (fat and carbohydrate) than day workers.

In short, gastric problems in shift and night workers may result from the summation of several factors: changes in dietary habits, consumption of substances that presumably help stay awake, and availability of food in the early morning hours. According to Costa 13, 20.0$70.0 \%$ of night workers complain about several gastric disorders, ranging from appetite and digestive disorders, heartburn, abdominal pains, constipation, borborygmus, and flatulence to more serious diseases such as chronic gastritis, gastroduodenitis, peptic ulcer, and colitis. Among day workers, this percentage drops to 10.0-25.0\%.

Shift work can also represent a risk factor for the development of cardiovascular diseases. However, the main difficulty in establishing a causal relationship between shift/night work and cardiovascular diseases is to eliminate confounding factors, which can act both as risk factors and as mediators in the development of these diseases. Age, tobacco consumption, obesity, and social status are some factors that require more in-depth investigation in order to determine the relationship between shift work and cardiovascular diseases 14

For example, in a group of truck drivers where the majority worked irregular schedules, there was a high prevalence of sedentary habits, inadequate dietary habits, and overweight 10,15. A large number of smokers and hypertensive individuals were also observed in this group 16 . These characteristics represent risk factors for various cardiovascular diseases such as systemic arterial hypertension, hypercholesterolemia, and coronary disease.
In other words, many shift and night workers display several risk factors for cardiovascular diseases, and such diseases do in fact occur within this professional category, exactly because individuals work at unusual times. The numerous risk factors involved hinder studies that include adequate control of confounding factors. Nevertheless, based on the results of several longitudinal studies, it is now possible to ascertain a strong association between shift work and coronary disease 6 .

Risk factors related to sleep disorders are also frequently observed in some professional categories (such factors can also simultaneously contribute to other disorders). For example, obesity, which is highly prevalent among truck drivers, is a strong independent risk factor for obstructive sleep apnea (OSA), defined as recurrent respiratory alterations during nighttime sleep resulting from obstruction of the upper airways 17 . Such nighttime respiratory interruptions lead to sleep fragmentation and activation of the sympathetic nervous system. Sleep fragmentation, typical of individuals with OSA, results in excessive diurnal sleepiness. A complex physiopathology sets in, including activation of the sympathetic nervous system, which can contribute to cardiovascular complications in individuals with OSA. In short, obesity, a risk factor for both OSA and cardiovascular disease, is highly prevalent among some professional categories, usually shift workers.

When dealing with shift and night workers, close attention should be given to sleep disorders, sleep-related complaints, and diurnal sleepiness, since these factors hinder adaptation to shift and night work. Such disorders no doubt result from disruption in the diurnal nature of the human species, which has to cope with the inversion of the sleep and wakefulness periods.

Several authors have described sleep for shift and night workers as shorter than that of day workers. Diurnal sleep also displays some structural differences, that is, the duration of the diurnal sleep phases is not the same as that observed in nocturnal sleep 18,19 . The result of this reduction leads to chronic sleep deprivation, typically observed in shift and night workers.

The relationship between shift work and several diseases such as cancer and diabetes has been investigated in some studies 20,21, but further research is required to establish conclusive findings 6 .

It might appear that other factors besides the work schedule itself may lead to the conclusion that night work is a risk factor for a series of diseases. However, several studies have 
demonstrated that inversion of the sleeping/ waking cycle by night work per se can be considered an isolated risk factor.

Reduction of diurnal sleep, for example, occurs due to a circadian effect; the duration of diurnal sleep depends on the time of the day in which it takes place 22. Morgan et al. 23 have recently suggested that the time-dependent differences in postprandial responses can also be related to the risk of several diseases among shift and night workers.

The fact that night workers do not show any signs or symptoms of a disease previously related to night work suggests the importance of individual differences in adaptation to work 24 . Individuals appear to deal with the several factors that influence adaptation to a given work schedule in different ways.

It is exactly in extreme situations that individual differences become most evident, as in night work. Inversion of the work schedule, which acts as a social synchronizer, generates a change in the phase relationships among the rhythms. This change occurs subsequently to a sudden change in the environmental synchronizer. This is exactly what happens with night workers or shift workers. In other words, a change in the temporal reference responsible for the entrainment of biological rhythms takes place. The result is disruption of the internal temporal order, as the resynchronization of the several rhythms does not occur at the same speed. Thus, differences between individuals in such disruption and the subsequent reestablishment of the internal temporal order become quite clear. Therefore, for the morning chronotype, staying alert during night shifts is more difficult than for the evening chronotype.

As for gender differences and adaptation to work, some studies have demonstrated that women's social role exerts an influence on the magnitude of their adaptation. This is because in many countries women are responsible for both household tasks and the children, thus bearing a double burden (work plus domestic chores) 25. However, there is strong evidence of an association between shift work and problems related to pregnancy. In a review of diseases related to shift work, Knutsson 6 highlights that consistent results have been observed between shift work and low birth weight, preterm birth, and miscarriage. The author also emphasizes that even in the absence of additional studies, pregnant women should avoid shift work or night work.

\section{Could knowledge of biological rhythms help shift workers?}

Monk 26 has published a review article on the role of chronobiology in minimizing problems faced by shift workers, with the following exciting title: What Can the Chronobiologist Do to Help Shift Workers?. Shift workers do need help, he says. Could knowledge of biological rhythmicity help them? No doubt it could, since the problems they face are not merely adjacent to work schedules, but are caused by disruption of the stability between the external and internal clocks.

An example is the phase changes in biological rhythmicity resulting from the inversion of sleeping and waking times experienced by shift and night workers. In other words, shift and night workers have to be alert during the phase opposite to their natural waking time. Knowledge of workers' biological rhythms would allow intervention in (and consequent adjustment of) such rhythms. Circadian phase indices could be used to investigate phase changes in workers' biological rhythms. Among these indices, the urinary melatonin metabolite 6-sulphatoxymelatonin (aMT6s) has been widely utilized in studies involving shift workers.

Barnes et al. 27 studied oil workers on a rotating system consisting of 2 -week day shifts (06:00-18:00) and a 2-week period of night shifts (18:00-06:00) throughout a sequence of day and night shifts. The results showed adaptation to night shifts by delaying the 6-sulphatoxymelatonin rhythm in the first week of the night shift period. Among the adjustments observed in night workers' biological rhythms, the phase delay prevails, matching the 10-hour delay in the sleep onset. In general, shift workers go to bed around 9:00 am (depending on the end of their shift), thus having the opportunity to enjoy the company of the family in the late evening hours 24,28

Barnes et al. 29 studied the crews of two offshore drilling rigs working under a one-week day (12:00-00:00) and one-week night (00:00-12:00) swing shift. Members of one crew $(n=11)$, studied in winter, showed no change in their 6-sulphatoxymelatonin rhythm during the night shift. Members of the other crew $(n=7)$, studied in summer, showed a significant phase advance in their melatonin rhythm during the night shift. Such data indicate that both the type of shift and the season influence the direction and degree of adaptation. This explains why melatonin onset does not always match sleep onset.

Some workers sleep either a few hours before starting work, or a few hours soon after 
finishing the night shift. On a study of female night workers, Moreno 30 observed that some women either delayed or advanced their sleep episodes as a function of their household tasks and activities involving the children. However, in some individuals this endogenous human capacity, that is, having more than one episode of sleep in a 24-hour period, is barely expressed. Their sleep follows a monophasic pattern; in other words, they tend to sleep only once a day.

At any rate, experiencing more than one period of sleep per day or taking naps has been suggested as one of the possible strategies to adapt to shift and night work.

Exposure to light as a means to promote adjustment of workers' biological rhythms is another strategy that has been studied for the last two decades. Several field studies by the National Aeronautics and Space Administration (NASA) resorted to long high-intensity exposures to produce adaptation to shift work 31,32 . It has also been demonstrated that short periods of exposure to light can produce the same effects as long periods of exposure to light. Another study has demonstrated that exposure to intermittent light (six 40-minute light pulses) produces an adjustment in the circadian rhythm. In an extensive review article, Burgess 7 recommends exposure to medium-intensity light and/or to intermittent light during night work as a strategy to promote adaptation to the work schedule. On the other hand, exposure to sunlight on the way home after a night shift may impede adaptation. Wearing sunglasses on the way home has also been recommended by several researchers 7,33 .

In addition to exposure to light at specific times and amounts, the administration of exogenous melatonin is another possible strategy for promoting adjustment of biological rhythmicity, but there have been few field studies on the subject 31 . Burgess 7 also points out that in the majority of these studies no index related to the circadian phase has been used, which makes it difficult to evaluate the actual adjustment of the rhythms. Moreover, the author points out that these studies were developed in laboratories, not in the field.

So far, only one field study where an index of the circadian phase was used to evaluate the effects of melatonin on the circadian rhythms of nurses and hospital clerical staff has been published 34 . The participants worked for seven consecutive night shifts, having seven days off. During two consecutive weeks, a low dose of melatonin $(0.5 \mathrm{mg})$ or placebo was taken at bedtime after the night shift. Melatonin produced larger phase delays than the placebo in 7 of the 24 subjects studied. Three subjects also experienced a phase advance due to the use of melatonin. The results of this study appear to be promising concerning the use of melatonin as a strategy to adapt to work. Nevertheless, additional studies are needed before the use of melatonin becomes common among shift and night workers.

\section{Final remarks}

Intervention with the purpose of reducing the impact caused by the dissonance between the environmental synchronizer and the circadian timing system should be based on two approaches. The first relates to changes in the organization of work shifts by establishing schedules that would minimize the risk of accidents and damage to the worker's health. The other involves measures that would facilitate adaptation of the worker's body, thus reducing internal desynchronization. The habit of taking naps, manipulating light stimulation by the use of artificial light, wearing sun glasses, and administration of exogenous melatonin seem to be promising measures, but further detailed studies are needed to make such measures safer and to preserve workers' health. 


\section{Resumo}

Este artigo tem o objetivo de apresentar alguns avanços cronobiológicos recentes relacionados à adaptação de trabalhadores a esquemas de trabalho noturno elou em turnos. Em um primeiro momento, é feita uma apresentação de conceitos cronobiológicos e de recentes achados nessa área relacionados à espécie humana. Em seguida, são apresentados possíveis efeitos dos horários de trabalho na saúde desses trabalhadores. Por último, são discutidas medidas de intervenção para possibilitar o ajuste da ritmicidade biológica dos trabalhadores como promoção à adaptação ao trabalho em turnos e noturno.

Trabalho Noturno; Trabalho em Turnos; Saúde Ocupacional; Cronobiologia

\section{Contributors}

C. R. C. Moreno and F. M. Louzada produced the article in collaboration.

\section{References}

1. Roenneberg T, Wirz-Justice A, Merrow M. Life between clocks: daily temporal patterns of human chronotypes. J Biol Rhythms 2003; 18:80-90.

2. Yoo SH, Yamazaki S, Lowrey PL, Shimomura K, Ko $\mathrm{CH}$, Buhr ED, et al. Period 2: luciferase real-time reporting of circadian dynamics reveals persistent circadian oscillations in mouse peripheral tissues. Proc Natl Acad Sci USA 2004; 101:5339-46.

3. Aschoff J. Endogenous and exogenous components in circadian rhythms. Cold Spring Harb Symp Quant Biol 1960; 25:11-28.

4. Brandstaetter R. Circadian lessons from peripheral clocks: is the time of the mammalian pacemaker up? Proc Natl Acad Sci USA 2004; 101:5699-700.

5. Albrecht U. The mammalian circadian clock: a network of gene expression. Front Biosci 2004; 9:48-55.

6. Knutsson A. Health disorders of shift workers. Occup Med 2003; 53:103-8.

7. Burgess HJ, Sharkey KM, Eastman CI. Bright light, dark and melatonin can promote circadian adaptation in night shift workers. Sleep Med Rev 2002; 6:407-20.

8. Piggins HD. Human clock genes. Ann Med 2002; 34:394-400.

9. Archer SN, Robilliard DL, Skene DJ, Smits M, Williams A, Arendt J, et al. A length polymorphism in the circadian clock gene per3 is linked to delayed sleep phase syndrome and extreme diurnal preference. Sleep 2003; 26:413-5.

10. Pasqua IC, Moreno CRC. Consumo de substâncias estimulantes e depressoras do sistema nervoso por motoristas de caminhão. Nutrição Brasil 2003; 2:4-11.

11. Waterhouse J, Buckey P, Edwards B, Reilly T. Measurement of, and some reasons for, differences in eating habits between night and day workers. Chronobiol Int 2003; 20:1075-92.

12. Assis MAA. Comportamento alimentar e ritmos circadianos de consumo nutricional dos coletores de lixo da cidade de Florianópolis: relações entre os turnos de trabalho [Tese de Doutorado]. Santa Catarina: Universidade Federal de Santa Catarina; 1999.

13. Costa G. Saúde e trabalho em turnos e noturno. In: Fischer FM, Moreno CRC, Rotenberg L, organizadores. Trabalho em turnos e noturno na sociedade 24 horas. Rio de Janeiro: Editora Atheneu; 2003. p. 79-98.

14. Boggild H, Knutsson A. Shift work, risk factors and cardiovascular disease. Scand J Work Environ Health 1999; 25:85-98.

15. Korelitz JJ, Fernandez AA, Uyeda VJ, Spivey GH. Health habits and risk factors among truck drivers visiting a health booth during a trucker trade show. Am J Health Promot 1993; 8:117-23.

16. Häkkänen H. Professional driving, driver fatigue and traffic safety. Helsinki: University of Helsinki; 2000.

17. Young T, Peppard PE, Gottlieb DJ. Epidemiology of obstructive sleep apnea. Am J Respir Crit Care Med 2002; 165:1217-39.

18. Akerstedt T. Work hours, sleepiness and the underlying mechanisms. J Sleep Res 1995; 4:15-22. 
19. Åkerstedt T. Work hours, sleepiness and accidents introduction and summary. J Sleep Res 1995; 4 Suppl 2:1-3.

20. Di Lorenzo L, Pergola D, Zocchetti C, L'Abbate N, Basso A, Panncciulli N, et al. Effect of shiftwork on body mass index: results of a study performed in 319 glucose-tolerant men working in a Southern Italian industry. Int J Obesity 2003; 27:1353-8.

21. Schernhammer E, Laden F, Speizer FE, Willet WC, Hunter DJ, Kawachi I, et al. Night shift work and risk of colorectal cancer in the Nurses' Health study. J Natl Cancer Inst 2003; 95:825-8.

22. Czeisler CA, Weitzman ED, Moore-Ede MC, Zimmerman JC, Knauer RS. Human sleep: its duration and organization depend on its circadian phase. Science 1980; 210:1264-7.

23. Morgan L, Hampton S, Gibbs M, Arendt J. Circadian aspects of postprandial metabolism. Chronobiol Int 2003; 20:795-808.

24. Monk TH, Folkard S. Making shiftwork tolerable. London: Taylor \& Francis; 1992.

25. Rotenberg L, Portela LF, Marcondes WB, Moreno CRC, Nascimento CP. Gênero e trabalho noturno: sono, cotidiano e vivências de quem troca o dia pela noite. Cad Saúde Pública 2001; 17:639-49.

26. Monk TH. What can the chronobiologist do to help the shiftworker? J Biol Rhythms 2000; 15:86-94

27. Barnes RG, Deacon SJ, Forbes MJ, Arendt J. Adaptation of the 6-sulphatoxymelatonin rhythms in shiftworkers on offshore installation during a 2 week 12-h night shift. Neurosci Lett 1998; 241:9-12.
28. Kogi K. Introduction to the problems of shift work. In: Folkard S, Monk TH, editors. Hours of work: temporal factors in work scheduling. New York: John Wiley; 1985. p. 165-84.

29. Barnes RG, Forbes MJ, Arendt J. Shift type and season affect adaptation of the 6-sulphatoxymelatonin rhythms in offshore oil rig workers. Neurosci Lett 1998; 252:179-82.

30. Moreno CRC. Fragmentação do sono e adaptação ao trabalho noturno [Tese de Doutorado]. São Paulo: Faculdade de Saúde Pública, Universidade de São Paulo; 1998.

31. Czeisler CA, Chiasera AJ, Duffy JF. Research on sleep, circadian rhythms and aging: applications to manned spaceflight. Exp Gerontol 1991; 26: 217-32.

32. Stewart KT, Hayes BC, Eastman CI. Light treatment for NASA shiftworkers. Chronobiol Int 1995; 12:141-51.

33. Eastman CI, Stewart KT, Mahoney MP, Liu L, Fogg LF. Dark goggles and bright light improve circadian rhythm adaptation to night-shift work. Sleep 1994; 17:535-43.

34. Sack RL, Lewy AJ. Melatonin as a chronobiotic: treatment of circadian desynchrony in night workers and the blind. J Biol Rhythms 1997; 12:595-603.

Submitted on 18/Aug/2004

Approved on 23/Aug/2004 